\title{
THEORY AND MEASUREMENTS OF BITUMEN BINDERS ADHESION TO AGGREGATE
}

The pavement as unit is able to perform services, provided that we ensure good synergy of layers and especially good adhesion between used materials. Adhesion knowledge allows to design suitable technology by preventing defects and to ensure service ability and life of pavement.

In the paper there is a theoretical analysis of problem of bitumen binders adhesion to aggregate, basic methodologies to evaluate this property and specific results achieved at measuring by the method STN 657089 and EN 12272-3. At the same time the results are compared from the type of aggregate point of view as one of the most important factors that influenced adhesion.

\section{Introduction}

The wearing surface of the road is exposed to both vertical and tangential forces caused by the moving vehicle. The bitumen elements and aggregate stripping from the tyre are torn out by the suction effect of the wearing course, thus causing the continual destruction of the wearing course. The loss of bitumen cohesion and adhesion between the bitumen and aggregate is a major cause of defects in bitumen road surfacing. By the traffic effects, ravelling occurs. It is caused by material fatigue and stress pressure in tyre/ surface contact area, weather effects, especially water which results in stripping the aggregate grains in the wearing surface (water is forced by the tyre engravement into the tyre/pavement contact area, and arises forces with similar effect as suction) and the ageing of the bitumen binder in the wearing surface which becomes harder and more fragile to the breaking.

The basis for the construction of the high quality wearing course with a long service life is the adhesion between the binder and the aggregate. It is important to achieve a strong bond among all materials during the service life at the varied climatic conditions. Adhesion knowledge allows to design a suitable technology, thus preventing defects and ensuring longer service life of the wearing course.

\section{Methodological Approach}

\subsection{Adhesion}

Generally, adhesion is defined as the affinity force between surface molecules of two materials that cause a close contact without chemical change. It depends on the interfacial surface tension and the binder wetting.

The ability of binder to cover aggregate (wetting ability) is called active adhesion. Passive adhesion expresses the binder coat resistance to the stripping from aggregate surface by the water effect. If the conditions of coating are properly designed and performed, there is no active adhesion [1].

Besides the mechanical interaction at the contact surface (liquid bitumen penetration into the pores of solid material), which depends on the physical properties of aggregate and bitumen - also mechanical adhesion exists. It is also necessary to ensure sufficient bond strength of physical and chemical bonds between contacted binder and aggregate - specific adhesion. Incipient chemical cohesion caused by the effect of chemical (interatomic) bonds is more energetically stable than physical cohesion initiated by a physical (intermolecular, van der Waals) bond effect [2].

\subsection{Theories of adhesion mechanism}

From the general point of view, adhesion is the force that bonds the binder to solid surfaces and prevents its tearing away. Several mechanisms have been used to explain adhesion between

Theories of adhesion mechanism

Tab. 1

\begin{tabular}{|l|l|l|}
\hline Theory & Mechanism & $\begin{array}{l}\text { Strength of } \\
\text { interaction }\end{array}$ \\
\hline adsorption (Bruyne) & van der Waals, H-bonding & $\begin{array}{l}\text { moderate } \\
\text { to strong }\end{array}$ \\
\hline diffusion (Voyutskii) & $\begin{array}{l}\text { inter-diffusion binder } \\
\text { molecules to solid material }\end{array}$ & variable \\
\hline $\begin{array}{l}\text { bonding (Bickerman, } \\
\text { mechanical interlock) }\end{array}$ & $\begin{array}{l}\text { mechanical diffusion of } \\
\text { binder to aggregate pores, } \\
\text { close contact wetting }\end{array}$ & variable \\
\hline surface energy theory & $\begin{array}{l}\text { binder and aggregate surface } \\
\text { with more critical surface } \\
\text { tension, wetting }\end{array}$ & variable \\
\hline $\begin{array}{l}\text { reactive theory, } \\
\text { chemical bonding }\end{array}$ & covalent bond & very strong \\
\hline
\end{tabular}

\footnotetext{
* Eva Remišová

Faculty of Civil Engineering, University of Žilina, Slovakia, E-mail: remisova@fstav.utc.sk
} 
materials [3]. We can say about none of them to be perfect and general. Some of them are presented in Table 1.

The adhesion is closely related to the surface properties of materials - binders and aggregates. Generally, material surfaces are characterized by the surface energy, esp. surface tension that influences their ability to adhere to each other and to a create strong bond.

Excess of acting forces in the surface level per length unit of a line on the surface is surface tension. Surface tension is positive when affects following the direction of surface contracting. If the bitumen surface tension is low and if the bitumen has affinity to aggregate surface, the bitumen is able to cover aggregate and adhere to its surface [4]. a) binder drop on adhere surface

$$
\left(\varphi<90^{\circ}\right)
$$

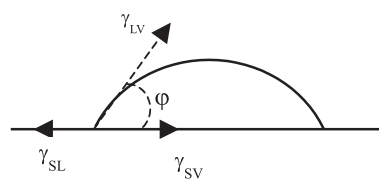

b) binder drop on non adhere surface $\left(\varphi>90^{\circ}\right)$

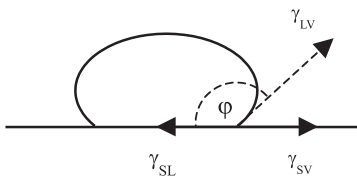

Fig. 1 Surface tensions between liquid and solid phases
Performance of bitumen - aggregate bond (liquid - solid phases) is with the presence of the gas phase, if this bond does not occur in vacuum. The calculation of the surface tension of the triple contact is difficult because surface interface tension is effected by all contact phases - solid phase, liquid phase and gas phase where the surface tension of solid phase is $\gamma_{S V}$, surface tension of liquid phase is $\gamma_{L V}$ and $\gamma_{S L}$ is interface tension between solid and liquid phases (fig.1).

The equilibrium (or stability) of surface tensions of interface of solid - liquid - gas phase is expressed generally in Young Dupré equation:

$$
\gamma_{S V}-\gamma_{S L}=\gamma_{L V} \cdot \cos \varphi
$$

where $\varphi\left[{ }^{\circ}\right]$ is contact angle between liquid drop and surface of solid material with the presence of air.

Direct relation exists between perfection of wetting and intensity of adhesion strength stability. Bond strength is changed analogously as $\cos \varphi$. Interface tension increases directly proportional with $\cos \varphi$, and the ability to coat solid material with the binder. If $\varphi=0$, total and spontaneous coating and adherence occur. If $\varphi=180^{\circ}$ coating cannot come into force.

Initial surface energy decreases during bitumen aggregate coating due to the absence of air membranes covering the liquid (bitumen) and solid materials (aggregate),while performing the work $W$ :

$$
W=\sigma_{S V}+\sigma_{L V}-\sigma_{S L}
$$

where: $\sigma_{S V}$ is surface energy of solid phase,

$\sigma_{L V}$ is surface energy of liquid phase,

$\sigma_{S L}$ is energy of solid - liquid phase interface.

Measurement of surface energies, interface energies and contact angles are difficult under the conditions of conventional laboratories. Thus, the comparison of properties of different surfaces with the binder is difficult because the measurement of the contact angle requires even surface of solid material and then the surface must be modified [5].

Specific value of the surface tension of the binder and aggregate contact above which spontaneous coating does not occur is the critical surface tension. Only binders with surface tension less than critical value will cover solid surfaces spontaneously.

It is necessary that bitumen have good wetting ability to create the stable coat on the aggregate. Wetting and adhesion perform on the phases interface and relate to the intermolecular forces. The bitumen covers aggregate surface well if its surface tension is low. Surface tension of bitumen decreases when temperature increases. The viscosity of bitumen decreases at higher temperature; bitumen covers aggregate well and adheres to the aggregate surface.

\section{Experimental measuring}

As mentioned above, it is difficult to measure adhesion as the force that bonds bitumen to aggregate therefore methodological techniques have been developed for evaluating adhesion by measuring the properties of the bitumen mixtures. Methods used to adhesion measurement are based on one of following principles:

- visual evaluation by estimation of uncovered surface of the aggregate by the water effect,

- adhesion measurement by the mechanical test (adhesion evaluating as the resistance to mechanical stresses),

- adhesion evaluation as the resistance to water by measuring mechanical property of mixture before and after tempering in water,

- evaluating the chemical adhesion.

The basic test method of adhesion evaluating in the Slovak Republic is the procedure which follows the technical standard STN 657089 - Determination of Adhesion of Asphalt Products to Aggregates from year 1982 [6]. According to this standard the adhesion of asphalt products to aggregates is the resistance of the asphalt film on the aggregate surface to the water displacement (passive adhesion). The adhesion influences asphalt mixtures quality and service life. This method also indicates the efficiency of adhesion additives.

The methods able to evaluate adhesion of the binders penetration 35 - 210, cut-back bitumen with the flow time $\mathrm{C} / 5 / 60$ to $170 \mathrm{~s}$ and $\mathrm{C} / 5 / 25$ to $70 \mathrm{~s}$ and asphalt anionactive emulsions to the aggregates. Dry aggregates and wet aggregates are covered by the 
tested bitumen. After 24 hours of tempering it is exposed to the effects of tempered water (at the temperature of $+60{ }^{\circ} \mathrm{C}$ res. $+40{ }^{\circ} \mathrm{C}$ ) for one hour. Adhesion is expressed as a mean value of stripping of the asphalt film on the grains of the aggregate surface. Thus, adhesion is accepted if some uncovered points appear on the surfaces of covered aggregate grains or stripped borders and corners on more than two grains of the aggregate. If there are larger stripped areas on the grains of aggregate surface (two and more aggregate chippings), adhesion is not acceptable.

The degree of stripped asphalt on aggregate surface is evaluated visually. In this way, the evaluation becomes subjective depending on the technician performing the test. Methodology, test specimen, and test procedure predetermine this test to the asphalt evaluation and aggregate adhesion used in asphalt mixtures.

The European standard prEN 12697-11 [7] belongs to this test group. Standard measures evaluate the compatibility between the aggregate and bitumen, expressed by visual observation of the loss of adhesion in uncompacted bitumen-coated aggregate mixtures in the presence of the water. Test specimen is also affected by mechanical load with the presence of water.

From the second group of tests that evaluates adhesion by the mechanical test is Vialit test. The test methodology is the base for European standard EN 12272-3 Determination of Binder Aggregate Adhesivity by the Vialit Plate Shock Test Method [8]. This standard specifies test methods for determining the binder - aggregates adhesion as two main components of surfacing.

The standard applies to the measurement of binder - aggregate adhesion and the influence of adhesion agents on adhesion characteristics as the aid to design binder - aggregate systems for surface dressing. This methods allows to evaluate adhesion of:

- hydrocarbon binders used for surface dressings,

- paving grade and modified bitumens,

- cut-back bitumens,

- asphalt emulsions,

- to all aggregate types (with size 6-8, 8-11, 11-16 and 4-6, 6-10, 10-14).

The principle is the measurement of the binder - aggregate adhesion after mechanical exposure. European standard specifies the test method for determining:
- mechanical adhesion of the binder to the aggregate - Vm (property to bond dry aggregate chippings with their natural dust and fine particles)

- active adhesion - Va (the property to bond dump aggregate chippings in their natural state in which they occur in the dumping sites)

- improvement of mechanical and active adhesion using some adhesive agents to the binder or to binder - aggregate interface.

In terms of the standard European requirements prEN 12271-5 [9], the value of mechanical adhesion and active adhesion has to be minimum $95 \%$ res. $90 \%$ to reach value 2 res. 1 (for value 0 there is no adhesion requirement).

The standard has three basic divisions:

- active adhesion and mechanical adhesion,

- wetting temperature,

- fragility temperature.

In the first part, the test procedure is defined according to the known test method Vialit and determining the active adhesion. In the second part, the treatment for the determinng wetting temperature at the lowest binder temperature before the spreading aggregate is described when the grinding of the aggregate is possible with minimum $90 \%$ adhesion ( 90 of 100 grains of aggregate remain adherent to the experimental plate). And the other treatment to determine fragility temperature at the temperature at which minimum $90 \%$ aggregate chippings remain bonded to the plate is carried out at Vialit premises.

The binder - aggregate adhesion is expressed by the total number of aggregate chippings bonded to the plate and the aggregate with the binder fallen off after test. The advantage of this test method is that it allows measuring and evaluating the adhesion with different types of binders and aggregates. At the same time, it is possible to verify adhesion agents efficiency. Test results are influenced by binder - aggregate adhesion and also by binder cohesion, especially at low temperatures.

\subsection{Experimental measuring - materials}

For experimental measurements of bitumen and aggregate adhesion by the above presented test procedures, we used aggregates from different local sources, especially from the northern

The aggregate composition

Tab. 2

\begin{tabular}{|c|c|c|c|c|c|c|c|}
\hline $\begin{array}{c}\text { Aggregate } \\
\text { content [\%] }\end{array}$ & Varín & Šuja & Biely Potok & Dubná Skala & Malužiná & Hanišberg & $\begin{array}{c}\text { Kamenec } \\
\text { p. Vtáčnikom }\end{array}$ \\
\hline $\mathrm{SiO}_{2}$ & 1.04 & 0.30 & 0.30 & 70.74 & 56.77 & 56.5 & 59.27 \\
\hline $\mathrm{Al}_{2} \mathrm{O}_{3}$ & 0.21 & 0.20 & 0.07 & 17.31 & 12.96 & 19.5 & 19.72 \\
\hline $\mathrm{Fe}_{2} \mathrm{O}_{3}$ & 0.20 & 0.10 & 0.25 & 5.65 & 4.77 & 6.50 & 5.82 \\
\hline $\mathrm{CaO}$ & 47.02 & 30.90 & 31.60 & 3.49 & 9.06 & 7.50 & 5.81 \\
\hline $\mathrm{MgO}$ & 6.86 & 21.40 & 20.70 & 0.63 & 2.68 & 5.00 & 2.17 \\
\hline
\end{tabular}


Slovakia, representing these rocks: limestone from the locality Varín, dolomite from two localities (Šuja, Biely Potok), granodiorite from the locality Dubná Skala, melaphyre from the locality Malužiná and andesite from two the localities (Hanišberg, Kamenec pod Vtáč-nikom), and bitumen binders from by-products in Slovnaft oil refinery, both paving grade and modified (with the SBS rubber) [10].

Measured bitumen properties

Tab. 3

\begin{tabular}{|l|c|c|c|}
\hline \multicolumn{1}{|c|}{ Binder } & $\begin{array}{c}\text { Penetration } \\
\text { at } 25^{\circ} \mathrm{C} \\
\text { in } 0.1 \mathrm{~mm}\end{array}$ & $\begin{array}{c}\text { Softening } \\
\text { point } \mathrm{R} \& \mathrm{~B} \\
\mathrm{v}{ }^{\circ} \mathrm{C} \text {. minimum }\end{array}$ & $\begin{array}{c}\text { Ductility } \\
\text { at } 25^{\circ} \mathrm{C} \text { in } \mathrm{cm} . \\
\text { minimum }\end{array}$ \\
\hline bitumen $70 / 100$ & 83.7 & 53 & 114.9 \\
\hline $\begin{array}{l}\text { modified } \\
\begin{array}{l}\text { Apollobit } \\
\text { MCA-S }\end{array}\end{array}$ & 93.9 & 75 & 62.2 \\
\hline
\end{tabular}

\subsection{Comparison of laboratory results}

Experimental measurements of adhesion was performed by two test methods, according to the standard STN 657089 and Vialit test [11].

After bitumen and aggregate having been mixed, the process of interaction between aggregate and bitumen begins. These processes are determined by chemical and physical-technical properties of aggregate. The aggregate composition is evaluated from both chemical or mineralogical point of view. The chemical structure has only indirect effect on the aggregate used. From mineral point of view, the aggregate contains mostly one dominant component and some minor mineral components. For example, the limestone rock consists of dominant component limestone, and silica, clay, micaous minerals as minor components. In term of adhesion, the content of $\mathrm{SiO}_{2}$ in aggregate is the most important. The bitumen - aggregate adhesion results by method of STN 657089 (tab. 4) and Vialit test (fig. 2) show that the content of $\mathrm{SiO}_{2}$ in aggregate has negative influence on the adhesion of bitumen. The basic aggregate with minor content of $\mathrm{SiO}_{2}$ has good adhesion of bitumens. The adhesion of acid aggregate and bitumens has mostly poor adhesion level.

The worst adhesion results obtained by the Vialit method show the aggregate with high content of $\mathrm{SiO}_{2} 70.74 \%$ granodiorite form Dubná Skala locality. On the contrary, the adhesion results with

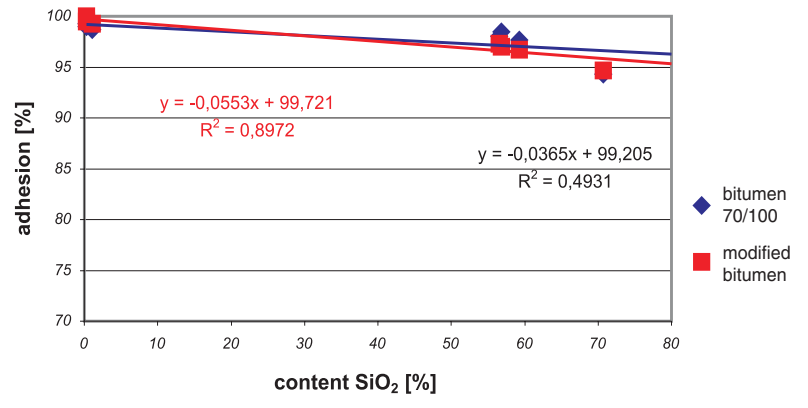

Fig. 2 The results of bitumens and aggregates adhesion

limestnones and dolomites with low content of $\mathrm{SiO}_{2}$ showed the best results of adhesion with all used bitumens by Vialit test 98.7 to $100 \%$ adhesion. These results were confirmed by both test methods, adhesion measuring of specimens aggregate with their natural dust and fines and specimens tempering in water. Neutral aggregate (andesites and melaphyre) had average adhesion values 96 to $100 \%$.

Regression analysis of relation to content of $\mathrm{SiO}_{2}$ in aggregate shows that there is a linear dependence between adhesion results and aggregate content of $\mathrm{SiO}_{2}$. This dependence obtained from the measurements with all used bitumens and aggregates and also with measuring dry aggregate and aggregate with their natural dust and fines, and also adhesion measuring of specimens tempered in water. From the analysis of these dependencies, we can conclude that the adhesion decreases in dependence on the content of $\mathrm{SiO}_{2}$. With the increase of $\mathrm{SiO}_{2}$ in aggregate about $1 \%$, the adhesion value decreases about $0.037 \%$ (paving grade bitumen) eventually with $0.055 \%$ modified bitumen.

From other mineral ingredients which can be found in the aggregate, some minor minerals that show an increased content of $\mathrm{Al}_{2} \mathrm{O}_{3}$ are important. These minerals with $\mathrm{SiO}_{2}$ have an apparent hydrophilic character in contrast with hydrophobic character of limestone. These minerals show very different reactions toward the bitumen binder and the water.

From these data it is evident that thickness of bitumen coat around the limestone chipping is essentially higher than around silica (quartz) chipping. On the surface of limestone chipping contents adsorption we can find centers in the form of limestone cations $(\mathrm{CaO})$, magnesia $(\mathrm{MgO})$ and ferrate $\left(\mathrm{Fe}_{2} \mathrm{O}_{3}\right)$, with the intense positive potential. The anion exchange of bitumen binder conducts to the strong binder film bonds.

The adhesion results of bitumens and aggregates by STN 657089

Tab. 4

\begin{tabular}{|c|c|c|c|c|c|c|c|}
\hline Binder & \multicolumn{7}{|c|}{ Adhesion } \\
\hline bitumen $70 / 100$ & \multicolumn{3}{|c|}{ good - suitable } & \multicolumn{3}{|c|}{ suitable - poor } & poor \\
\hline modified & \multicolumn{3}{|c|}{ good } & \multicolumn{3}{|c|}{ good - suitable } & poor \\
\hline \multirow[t]{2}{*}{ Aggregate } & dolomite 2 & dolomite 1 & limestone & andesite 1 & melaphyre & andesite 2 & granodiorite \\
\hline & \multicolumn{3}{|c|}{ basic } & \multicolumn{3}{|c|}{ neutral } & acid \\
\hline
\end{tabular}


Adhesion results comparison in dependence on the content of limestone $(\mathrm{CaO})$ and magnesia $(\mathrm{MgO})$ show that rocks with high content of these minerals have good adhesion (fig. 3 and fig. 4). The dependence is expressed in regression function. Parameters $\mathrm{A}$ and $\mathrm{k}$ depend on the type of binder and also the system of measuring (measurement with washed and dry aggregate, aggregate with their natural dust and fines, measurement of experimental samples tempered in water).

Positive effect of $\mathrm{CaO}$ and $\mathrm{MgO}$ content in the aggregate on the bitumen binder adhesion was confirmed by the adhesion results tested by standard STN 657089 .

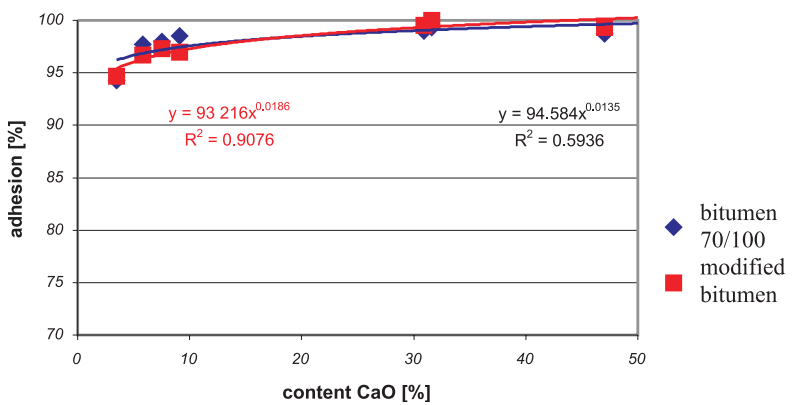

Fig. 3 The adhesion results of bitumen binder to aggregate in dependence on content $\mathrm{CaO}$ in aggregate

From the measurement results based on the comparison of the observed specimens we can conclude that the best level of adhesion was exibited with basic aggregates with the high of $\mathrm{CaO}$ content and $\mathrm{MgO}$, then with neutral aggregates, and from the adhesion point of view the acid aggregate with the high content of $\mathrm{SiO}_{2}$ and $\mathrm{Al}_{2} \mathrm{O}_{3}$ had the worst results with all used binders. The modified bitumen adhesion to aggregate had better results than paving grade bitumen adhesion. Regarding to a limited space of the paper, detailed adhesion results of binders to aggregates at different conditions (wet aggregate, aggregate with dust on the surface, different temperatures, specimens tempering in water, etc.) are not presented in paper.

\section{Conclusions}

Most workplaces in other countries have developed their own laboratory test methods measuring the adhesion, and their own specific criteria of evaluation of bitumen adhesion to aggregate. At our workplace we evaluated the possibility of using the new adhesion test and evaluation method Vialit. Test results and their

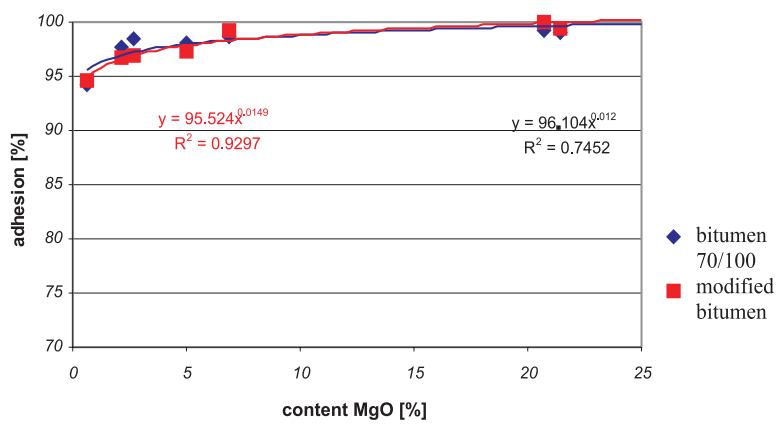

Fig. 4 The adhesion results of bitumen binder to aggregate in dependence of content $\mathrm{MgO}$ in aggregate

comparison with the results obtained from measuremets by STN 657089 show the suitability of this method to determine adhesion of different binders and aggregates. The test method enables to determine the adhesion and at the same time to study different factors effecting the adhesion: the type of aggregate and binder, surface characteristics of aggregate, temperature sensitivity of binder-aggregate bond, resistance to water, etc. Considering the simplicity of the test equipment servicing, this test method can be included among the general tests of road building materials.

The adhesion results of bitumens and aggregates by STN 657089

Tab. 5

\begin{tabular}{|c|c|c|c|c|c|c|}
\hline Binder & \multicolumn{6}{|c|}{ Adhesion } \\
\hline bitumen 70/100 & poor & suitable & suitable & poor & poor & suitable \\
\hline modified & poor & good & good & suitable & good & good \\
\hline content & granodiorite & andesite 2 & andesite 1 & melaphyre & dolomite 1 & dolomite 2 \\
\hline CaO & $3.49 \%$ & $5.81 \%$ & $7.50 \%$ & $9.06 \%$ & $30.90 \%$ & $47.02 \%$ \\
\hline
\end{tabular}

The adhesion results of bitumens and aggregates by STN 657089

\begin{tabular}{|c|c|c|c|c|c|c|}
\hline Binder & \multicolumn{6}{|c|}{ Adhesion } \\
\hline bitumen 70/100 & poor & suitable & poor & suitable & suitable & suitable \\
\hline modified & poor & good & suitable & good & good & good \\
\hline content & granodiorite & andesite 2 & melaphyre & andesite 1 & limestone & dolomite 2 \\
\hline Mg0 & $0.63 \%$ & $2.17 \%$ & $2.68 \%$ & $5.00 \%$ & $6.86 \%$ & $21.40 \%$ \\
\hline
\end{tabular}




\section{References}

[1] BENEŠ, V.: Asphalts, production and application, Praha SNTL, 1961

[2] SCHULZE, W., TISCHER, W., ETTEL, W., LACH, V.: Non-cement mortars and concretes, 1990

[3] BAREŠ, R.: Composite materials, Praha SNTL, 1988

[4] MOORE, W. J.: Physical chemistry, SNTL Praha, 1981

[5] KELLO, V., TKÁĆ, A.: Physical chemistry, Alfa Bratislava, 1969

[6] STN 65 7089: Determination of adhesion of asphaltic products to aggregates, 1982

[7] PREN 12697-11 Determination of the compatibility between aggregate and bitumen

[8] EN 12272-3: Determination of binder aggregate adhesivity by the Vialit plate shock test method 2003

[9] PREN 12271-5: Binder - aggregates adhesivity

[10] SLOVAK GEOLOGICAL INSTITUTE: Geological exploration, Final reports and calculation resources, Slovak geological institute Bratislava

[11] REMIŠOVÁ, E.: Theoretical aspects of bitumen binders' adhesion to aggregates, dissertation work, Univerzity of Žilina 2000 